\title{
FAMÍLIA DE DEUS, VALORES NEOLIBERAIS: DAMARES ALVES E
}

\author{
A DEPURAÇÃO DE DIREITOS \\ Family of God, neoliberal values: Damares Alves and the rights' depuration
}

Emanuelle Gonçalves Brandão Rodrigues ${ }^{1}$

Carolina Cavalcanti Falcão ${ }^{2}$

\begin{abstract}
RESUMO
Este trabalho analisa o desempenho do Ministério da Mulher, Família e Direitos Humanos para compreender as formas contemporâneas de ativismo político do campo evangélico brasileiro, discutindo como a família abriu um espaço político-institucional valioso para a atuação de um ativismo religioso de feição neoliberal no país. Nosso marco teórico-metodológico é a Teoria do Discurso de Laclau e Mouffe (2015), que nos ajuda a pensar como os sentidos atrelados aos significantes não são dados a priori e sim num processo contingencial. A análise aponta que, longe de divergirem, pautas neoliberais e conservadoras são o fundamento do governo Bolsonaro, cujos discursos da ministra Damares Alves figuram como a materialização dessa relação, associando a promoção de valores familiares à privatização dos direitos sociais.
\end{abstract}

Palavras-chave: Ativismo religioso; neoliberalismo; conservadorismo moral; valores familiares; Damares Alves.

\begin{abstract}
This paper analyzes the Ministry of Women, Family, and Human Rights performance to understand the contemporary forms of political activism in the Brazilian evangelical field, discussing how the family raised a valuable political-institutional space for the enhancement of neoliberal religious activism. Our theoretical-methodological framework is the Theory of Discourse, from Laclau and Mouffe (2015), which assumes that the meanings concerning signifiers are not given beforehand, but in a contingent process. The analysis points out that, far from diverging, neoliberal and conservative agendas are the very foundation of Jair Bolsonaro's government, arguing that Minister Damares Alves discourse figures as the materialization of this relationship, associating the promotion of family values with the privatization of social rights.
\end{abstract}

Keywords: Religious Activism; Neoliberalism; Moral Conservatism; Family Values; Damares Alves

\section{Introdução}

Neste trabalho, propomos uma análise sobre o Ministério da Mulher, Família e Direitos Humanos (doravante, MMFDH) ${ }^{3}$ como maneira de compreender as formas contemporâneas de

\footnotetext{
${ }^{1}$ Doutaranda em Comunicação da Universidade Federal de Pernambuco (UFPE). Professora Substituta do Curso de Relações Públicas da Universidade Federal de Alagoas. E-mail: egbrodrigues@gmail.com.

${ }^{2}$ Doutora em Comunicação pela Universidade Federal de Pernambuco. Pesquisadora Pós-Doc no Programa de Pós-Graduação em Direitos Humanos (PPGDH) da UFPE. E-mail: carolinacfalcao@gmail.com.

${ }^{3} \mathrm{O}$ Ministério foi criado no primeiro ano do governo Bolsonaro, em 2019. Visto como um aceno à sua base mais conservadora, o MMFDH é comandado, desde então, pela advogada Damares Alves, figura reconhecida por sua
} 
ativismo político do campo religioso evangélico no Brasil. O corpus de análise deste trabalho compreende um conjunto de textos publicados em portais de comunicação do país entre 2018, quando foram anunciados os ministros do governo Bolsonaro, e durante 2019, primeiro ano de atuação do MMFDH. O referido material chamou nossa atenção, uma vez que os textos trazem no centro de seus argumentos a figura da ministra da referida pasta, Damares Alves ${ }^{4}$, e projetam efeitos de sentido de certa forma ambíguos sobre o caráter conservador e progressista da ministra. Percebemos que essa estratégia discursiva abre uma noção interessante em torno de tais significantes, reforçando nossa hipótese inicial de que, longe de se basear apenas nas chamadas "pautas morais", tal forma de atuação se constitui a partir de afinidades estruturantes, e cada vez mais refinadas, com a ideologia neoliberal. O marco referencial teórico e metodológico que nos ajuda a navegar por essa proposta exploratória e analítica é a Teoria do Discurso de Ernesto Laclau e Chantal Mouffe (2015), da qual nos valeremos para pensar sobretudo como os sentidos atrelados aos significantes não são dados a priori e sim num processo sempre contingencial.

Laclau e Mouffe (2015) explicam que existem três características básicas em sua Teoria do Discurso. São elas: (1) o discursivo como condição da emergência dos sentidos; (2) o caráter material de toda estrutura discursiva e, por fim, (3) a produtividade do discurso. A primeira proposta estabelece que todo objeto só pode ser inteligível se tomado em sua discursividade. Isto é: um terremoto é de fato um evento que acontece e que não obedece a nenhum comando humano. No entanto, "se sua especificidade como objeto será constituída em termos de um fenômeno natural ou como expressão da ira de Deus" (Ibidem, p. 181) depende dessa estruturação do campo discursivo. A segunda prevê que a materialidade do discurso não se verifica na unificação da experiência ou da consciência de um sujeito fundante, consciente do que diz, mas em diversas posições de sujeito que se articulam ${ }^{5}$. Por fim, o discurso orientado por uma prática articuladora é capaz de produzir "um maior alargamento do campo das

\footnotetext{
atuação como assessora parlamentar de nomes como Magno Malta e na Associação de Juristas Evangélicos (Anajure).

${ }^{4}$ Advogada e pastora evangélica, Damares Alves possui mais de 20 anos de atuação política como assessora parlamentar. Seu último cargo antes de assumir o MMFDH foi de assessora do senador e pastor Magno Malta (PRES).

${ }^{5}$ A articulação, na Teoria do Discurso, dá conta da própria noção de discurso como prática. Nosso argumento de que o discurso de Damares ora visto como conservador ora visto como progressista, revela, na verdade, o funcionamento do discurso como articulação de sentidos do que é visto como conservador ou progressista e não como essências em si mesmo. Essa articulação é sempre contingente e transitória, marcada pelas relações hegemônicas que se estabelecem num dado momento.
} 
categorias que podem dar conta das relações sociais" (Ibidem, p. 184), se apresentando como uma totalidade relacional.

A Teoria do Discurso realiza, assim, a tarefa de compreender o social a partir da apreensão de sentidos que se articulam em regularidades discursivas. Esses sentidos estão em constante disputa e no caso analisado, percebemos como o tensionamento entre o que seria uma política conservadora ou progressista indica uma certa incompreensão sobre as densidades do ativismo político no campo religioso no atual cenário brasileiro. Essa percepção dá sustentação ao nosso argumento de que o referido ministério, comandado por Damares Alves, propõe a mais efetiva síntese neoliberal do atual governo brasileiro. É justamente no processo de compreender como esses sentidos se constituem nas dobras entre o liberal conservador e progressista, que acontece, como o próprio Laclau (2008) explica, a transição do ontológico para o político em sua teoria.

O trabalho está dividido em quatro seções, cujos objetivos são descritos a seguir. $\mathrm{Na}$ primeira seção, apresentamos nosso ponto de partida, assentado nos vários duplos (conservador-liberal, ideológico-técnico etc.) que descrevem via de regra a forma de atuação institucional do governo Bolsonaro. Nosso objetivo é situar, dentro dessa leitura, o papel do Ministério comandado por Damares Alves e lançar as bases das primeiras problematizações sobre esses pares. Na segunda seção, assumimos a perspectiva global que encampa as afinidades entre neoliberalismo e o novo conservadorismo moral, de forma a mostrar como tal fenômeno se comporta em latitudes políticas distintas. Nosso objetivo é compreender como, no Brasil, a "onda conservadora" (BURITY, 2018) se conecta a uma série de ocorrências transnacionais ao mesmo tempo em que suscita contingências específicas, associadas sobretudo à emergência meteórica da agenda "liberal na economia e conservadora nos costumes" de Jair Bolsonaro nas eleições de 2018.

A terceira seção se detém na família como lugar privilegiado de observação desse duplo liberal-conservador. Nesse sentido, o trabalho se ocupa de investigar e conhecer as principais argumentações do Ministério sobre o valor da família na proposição de políticas públicas. Nosso objetivo é discutir como a família abriu um espaço político-institucional valioso para a atuação de um ativismo político neoliberal do campo religioso evangélico no país. Na quarta seção, nos dedicamos à compreensão desse ativismo, cuja genealogia está fortemente vinculada ao processo de redemocratização do país. Trata-se de um esforço de apreensão do escopo desse ativismo, orientado por uma cultura pública, cujas bases iniciais se deram numa perspectiva de 
presença legislativa e passaram a se estender de tal maneira que encontraram um campo de institucionalidade inédito com a presidência bolsonarista.

\section{O ponto de partida: desconstruindo a antítese "liberal na economia e conservador nos costumes"}

É importante pensarmos como as modulações entre progressista e conservador encontram guarida em outro duplo, de igual alcance no bolsonarismo, que é o par técnico e ideológico. Nesse sentido, queremos iniciar nosso trabalho a partir de uma reflexão do jornalista Ricardo Rangel (2020) para o blog da Revista Veja. No texto, ele pergunta: "Com ala técnica assim, quem precisa de ala ideológica?" para argumentar sobre o caso de Carlos Decotelli para sucessão de Abraham Weintraub na pasta da Educação ${ }^{6}$. Ele utiliza o caso para discorrer sobre as várias incidências de plágio, mentiras e qualificações insufladas nos currículos da equipe ministerial do presidente Jair Bolsonaro.

Além de desconstruir o discurso recorrente sobre uma suposta divisão entre alas técnica e ideológica nos ministérios bolsonaristas, o texto de Rangel propõe uma análise ainda mais enfática: não existiria uma ala técnica no governo federal. Sua pergunta, retoricamente colocada para elucidar o caráter ideológico do governo Bolsonaro, reverbera em nós algumas inquietações. A primeira delas está na assunção de que, de fato, possa haver quadros técnicos e ideológicos, assim, claramente delimitados. Essa perspectiva de diferença, aliás, norteia toda a crítica do colaborador do blog, como quem aponta uma falcatrua ("O currículo do ex-futuroministro não é mais fantasioso, no entanto, do que a ideia de que exista de fato uma "ala técnica" no governo", diz Rangel se referindo ao Lattes de Decotelli). A segunda inquietação surge do suposto antagonismo entre técnica e ideologia, o que sugere uma certa procedência da primeira em relação à segunda.

Dentro dessa lógica que vê uma diferença evidente entre técnica e ideologia, percebemos que a forma personificada desse binarismo se expressa nas figuras do ministro da Economia e da ministra da Mulher, Família e Direitos Humanos, Paulo Guedes e Damares Alves, respectivamente. A partir desse duplo, é comum encontrarmos análises políticas na mídia que associam Guedes ao papel da racionalidade econômica, uma espécie de fiador neoliberal do projeto bolsonarista para o Brasil; por outro lado, Damares é posta em um certo lugar de irracionalidade religiosa e infantilidade feminina, uma cortina de fumaça capaz de

\footnotetext{
${ }^{6} \mathrm{O}$ economista e professor carioca Carlos Decotelli foi nomeado Ministro da Educação em 25 de junho de 2020 e renunciou ao cargo cinco dias depois, devido a inconsistências sobre sua titulação. REVISTA RELEGENS THRÉSKEIA - 2021 - UFPR
} 
distrair a opinião pública. Apenas essa diferença entre os dois personagens encampa por si só um repertório valioso de representações que nos ajudam a pensar as formas simbólicas nas quais as noções de técnica e ideologia se constituem e se hierarquizam. Mas é nos efeitos de sentido dessa diferença que parece ser tão evidente que queremos nos deter, mais precisamente nos atentando aos desdobramentos observados a partir do técnico e do ideológico que incidem, respectivamente, sobre mais um par relevante no atual cenário brasileiro: a racionalidade econômica e a moralidade religiosa.

Nesse sentido, localizar as falas e posicionamentos de Damares Alves à frente do MMFDH no espectro de um campo religioso-conservador não está no todo equivocado, mas é insuficiente, entendemos, para uma análise conjuntural dos referentes históricos que ela mobiliza em seu discurso. Essas associações produzem sentido, mas não dão conta da complexidade do cenário em que Alves emerge como ator político detentor de um capital simbólico que extrapola os limites do que poderia ser chamado de religioso. Como ativista política de causas do campo evangélico, ela levanta pautas que vão muito além do espectro do conservadorismo, agenciando debates que traduzem sua aliança com o projeto neoliberal bolsonarista, aquele através do qual ela chegou ao poder. Longe de constituir um contrassenso, a aliança neoliberal-conservadora é o que tem permitido às elites políticas e econômicas do país sua perpetuação como classe hegemônica, que atua no sentido de reproduzir valores familiares cristãos dentro de uma compreensão de família privada que confere aos seus membros a responsabilidade plena pela educação, saúde, bem-estar e sobrevivência dos filhos.

Considerando que uma das bases eleitorais mais consistentes do governo Bolsonaro é formada por cristãos conservadores, neste artigo partimos da premissa de que as pautas levantadas por esse público possuem profundas afinidades com a racionalidade neoliberal pela qual se embasam agentes políticos com ou sem a mesma filiação religiosa desses grupos. A novidade está no modo como vão articular seus discursos de forma coerente, a despeito de suas diferenças ideológicas. A esse respeito, Cooper (2019) vai localizar na concepção de família como a fundação da ordem social e econômica o ponto de convergência entre neoliberais e neoconservadores. Essa articulação se evidencia nas falas da ministra Damares Alves, a qual defendemos ser uma articuladora mais "técnica" do que se imagina do projeto neoliberal do governo.

É nesse sentido que a lei do mercado, fundada na troca e na concorrência, é assumida como uma lei natural, passando a responsabilizar o pobre pela pobreza e reorganizar a noção de direito a partir da propriedade privada. E o exercício desse poder é absolutamente 
moralizado, de modo que todo sacrifício possa ser justificado em nome da autoridade da lei, a representação do poder de Deus. A família, não por acaso, passa a se constituir tanto como sujeito de direito como propriedade privada da autoridade familiar, esta predominantemente regida sob a estrutura patriarcal capitalista.

\section{Neoliberalismo iliberal: tendências globais, contingências locais}

Refletindo sobre as atuais características iliberais do neoliberalismo, Éric Fassin (2020) chama a atenção para as características peculiares das atuais formações populistas, focadas sobretudo num forte (e violento) apelo contra as políticas sexuais e seus desdobramentos. Seu principal argumento é que a ascensão de nomes como Donald Trump nos Estados Unidos, Viktor Orbán na Turquia ou Jair Bolsonaro no Brasil desenha as novas direções dos atuais arranjos neoliberais no Norte ou Sul globais, em que discursos anti-intelectuais e de proteção aos valores tradicionais fomentam uma agenda política cada vez mais endossada em eleições pelo mundo. Para o autor, um diagnóstico que não leva em conta as afinidades entre neoliberalismo e neoconservadorismo desconsidera, no mínimo, o papel estratégico do Evangelicalismo na promoção do capitalismo e a dimensão moral do neoliberalismo ao longo da história.

Mesmo sendo um fenômeno de contornos globais, é possível perceber que as densidades políticas de cada cenário determinam como esses arranjos vão se manifestar e se tornar conhecidos. Assim, se em países do Norte da Europa, a política populista desenvolve convergências em que a defesa de valores morais centrados na família é capaz de gerar efeitos muitas vezes anti-islâmicos ou xenofóbicos, é possível argumentar como na América Latina esse arranjo se dá em demandas específicas, situadas em latitudes próprias. É o caso, por exemplo, do plebiscito de paz $^{7}$, organizado em 2016 pelo governo colombiano de Juan Manuel Santos. No debate público sobre a escolha entre o "Sim" (em favor de um acordo com as FARC) e o "Não" (contrário ao processo de paz), a segunda opção foi vencedora com uma margem pequena (50,2\% votaram contra e $49,8 \%$ a favor do acordo).

Do lado vencedor, destacou-se um afiado trabalho ativista de grupos religiosos (cristãos evangélicos e carismáticos) que articularam um discurso que previa, na aquiescência com as FARC, um movimento de anistia, em que o cidadão médio seria impactado com o aumento de

\footnotetext{
${ }^{7} \mathrm{O}$ referendo na Colômbia foi um plebiscito de consulta à população como forma de conduzir um acordo de paz entre o governo colombiano e as FARC, pondo fim a mais de 30 ano de conflitos sangrentos.
} REVISTARELEGENS THRÉSKEIA - 2021 - UFPR 
impostos e ameaçado pela "ideologia de gênero". Assim, a família tradicional estaria na linha de frente de um perigo duplo, como explica Winifred Tate (2016) ao analisar o material de campanha do "Não", em que se previa, com a aprovação do acordo de paz, que o país cairia no controle de uma ditadura comunista e da passagem para uma ideologia de gênero. Em outras palavras, citando um dos materiais analisados, "um compromisso entre o governo colombiano e as FARC levaria à iminente tomada do grupo marxista e à destruição dos "valores familiares" e da ordem pública" (TATE, 2016, n/a).

Discutindo como a onda conservadora se deu na América Latina, Ailynn Torres Santana (2020) sugere que há em curso um processo de desdemocratização geral em que a ameaça aos direitos das mulheres e das pessoas LGBTQIA+ possui um papel central. Desenhando os desdobramentos desse processo no subcontinente, ela explica:

O combate ou a redução de direitos [de mulheres e LGBTIQ+] têm sido verificados em programas governamentais e também na maior presença, ação e implantação do neoconservadorismo com base religiosa. Com efeito, a maré neoconservadora integra atores de diferentes perfis, muitas vezes relacionados: atores políticos com programas de direita e extrema direita; fundamentalismos ou neointegrismos religioso; câmaras de negócios e atores econômicos neoliberais e conservadores de longa data, presentes em governos de diferentes signos políticos (Ibidem, p. 10).

No Brasil, o cenário de manifestação mútua entre o conservadorismo e o neoliberalismo produziu o bolsonarismo a partir de um efeito bivalente. Como explica Letícia Cesarino (2020): "Longe de se resumir a uma guerra cultural no campo das políticas de identidade, o bolsonarismo tem como pilar constitutivo um eixo neoliberal que é normalmente obscurecido pelo eixo populista-conservador" (Ibidem, p. 539). Nesse processo, argumenta a autora, a distinção entre os dois polos é apenas aparente, uma vez que não há como separar o nível superestrutural (conservador nos costumes) do infraestrutural (liberal na economia). Assim, é interessante notar como mesmo na defesa de uma pauta "clássica" da agenda neoliberal, como é o caso da discussão sobre a privatização das universidades públicas, é possível identificar na suposta fala técnica de Guedes uma inflexão conservadora e moralizante.

O caso mais recente é de uma reunião com o Conselho de Saúde Suplementar, realizada em 27 de abril de 2021. Sem saber que o encontro estava sendo transmitido ao vivo pelo Facebook, o ministro afirmou: "Vocês estão vendo o que está virando a universidade federal. Paulo Freire. Ensinando sexo para crianças de 5 anos. Todo mundo... maconha em quantidade, maconha, bebida, droga dentro da universidade. Estado caótico" (ROCHA, 2021, n/a). Na outra ponta, quando discute a regulamentação do aborto no país, Damares Alves o faz não numa 
perspectiva antagonista, mas num processo de reconhecimento e proposição. Quando perguntada sobre o tema em entrevista para a BBC Brasil, em dezembro de 2019, ela explica:

Eu tenho tanta coisa no Brasil para proteger a mulher, porque eu vou à rua pedir só aborto? Nós temos uma legislação no Brasil que garante à mulher em caso de estupro fazer o aborto, em risco de vida para a mãe e em caso de anencefalia. A legislação está lá, [...] eu não vou fazer ativismo contra ou próaborto, vou cuidar de mulheres, levar comida e capacitação profissional (SENRA; KRIEZIS, 2019, n/a).

Mais do que discutir o que tais posicionamentos representam dentro de uma agenda liberal-conservadora, nossa proposta é entender como eles significam nesse discurso que tem na família um repertório de moralização, cuidado e proteção. Nesse processo, entendemos que a mesma racionalidade que atravessa as falas de Guedes se encontra na resposta de Alves, o que ressalta o argumento de Fassin (2020) sobre o programa neoliberal, que sempre incluiu uma dimensão moral atenta ao lugar de responsabilização pelas falhas e limitações do indivíduo. Ou, como pontua Brown (2021), o neoliberalismo substituiu a ideia de Estado social pela ideia de liberdade econômica dos indivíduos, atrelada a uma ordem moral que emana da "moralidade tradicional". Assim, suspendem-se as intervenções nas hierarquias, nas exclusões, nos racismos, nos sexismos e na heteronormatividade que há tanto tempo sustenta a nossa ordem, alimentando "uma cultura política que diz: não, a liberdade e o bem repousam nas ordens morais tradicionais" (Ibidem, n/a).

É esse diapasão que permite que tanto as propostas de privatização das universidades públicas quanto as políticas de saúde das mulheres, por exemplo, se inscrevam numa mesma ordem de moralização. Assim, o pânico moral que acusa as instituições federais de ensino superior de promover "sexo para crianças de 5 anos" (daí a justificativa para a privatização) ou a retórica que prioriza "levar comida e capacitação profissional" para mulheres, em detrimento da discussão sobre saúde reprodutiva, são apenas algumas das formas convergentes com que neoliberalismo e conservadorismo se constituem. Há nessas falas um sentido de enfraquecimento do serviço público que, além de enfatizar uma lógica de mercado supostamente mais eficiente (por que discutir regulamentação do aborto se há tanto para se preocupar?, é o que diz Damares Alves) produz uma fragmentação da ideia de direito social.

\section{A família de Deus como produto do capital: neoliberalismo, neoconservadorismo e religião no Brasil atual}


Damares Alves ganhou notoriedade na mídia quando foi anunciada como futura ministra de Jair Bolsonaro, pouco depois de sua vitória nas eleições de 2018. No evento de posse, em 2 de dezembro de 2019, a fala de Alves, que assumiria a então recém-criada pasta da Mulher, Família e Direitos Humanos, foi destaque nos diversos veículos de comunicação e nas redes sociais, cuja ênfase recaiu sobre a seguinte afirmação: “O Estado é laico, mas esta ministra é terrivelmente cristã” (VIVAS, 2019, n/a). Embora não tenha sido a primeira figura evangélica a navegar pelo campo político-institucional dos Direitos Humanos ${ }^{8}$, a ela foi atribuída a imagem de uma mulher fundamentalista e irracional, algo muito diferente daquilo que indicava seu currículo com larga experiência política e jurídica com temas relacionados à família.

Em seu discurso de apresentação, Damares Alves afirmou que a família brasileira corria riscos em virtude de uma suposta doutrinação ideológica de crianças e adolescentes que, segundo ela, estava em curso em governos anteriores. A ministra se referia especialmente a um decreto publicado em 2009 pelo presidente Luís Inácio Lula da Silva (PT) em favor da desconstrução da heteronormatividade e respeito pela diversidade sexual e de gênero. $\mathrm{O}$ documento, que integrava a terceira edição do Programa Nacional de Direitos Humanos (PNDH), propunha “incluir nos sistemas de informação do serviço público todas as configurações familiares constituídas por lésbicas, gays, bissexuais, travestis e transexuais" (BRASIL, 2009, p. n/a), o que se constituiu como uma afronta aos valores familiares defendidos pela ministra.

Em um jogo de discurso aparentemente inofensivo, Alves afirmou que, a partir daquele momento, "todas as políticas públicas neste país terão que ser construídas com base na família" (Ibidem). Da forma como foi colocado, o discurso nos leva a entender que essas políticas não eram voltadas para o interesse público, pois este seria formado por pessoas que constituem agrupamentos familiares tradicionais. Mas não era disso que a ministra tratava, pois ela estava se referindo a uma composição familiar muito específica e restrita à sua visão de mundo, fortemente embasada sobre os pilares do cristianismo. Nas matérias dos maiores veículos de comunicação do país, a exemplo de $O$ Globo, Damares Alves integrava o grupo de membros conservadores da ala ideológica do governo, o que implicava, nessa lógica, estar do lado oposto de ministros liberais, a exemplo de Paulo Guedes (Economia), Sérgio Moro (à época da Justiça) e Tereza Cristina (Agricultura), estes fortemente apoiados pelos grandes grupos de Comunicação.

\footnotetext{
${ }^{8}$ Em 2013, tivemos a eleição do pastor Marco Feliciano, apoiado pela presidência de Dilma Rousseff (PT), para a presidência da Comissão de Direitos Humanos e Minorias (CDHM) da Câmara Federal. REVISTA RELEGENS THRÉSKEIA - 2021 - UFPR
} 
Mas como discutimos, conservadorismo e neoliberalismo têm mais afinidades do que distanciamentos, especialmente quando consideramos suas versões atualizadas, fazendo parte de uma mesma lógica governamental. No governo Bolsonaro, os valores familiares são um ponto de encontro entre essas duas perspectivas ideológicas, pois é a partir delas que se podem justificar as políticas que ao mesmo tempo fazem da família um sujeito de direito e seus membros os únicos responsáveis pela sua sobrevivência. Cooper (2019) faz uma análise bastante reveladora nesse sentido, apontando para uma aliança entre neoliberais e os novos conservadores como uma resposta às políticas de bem-estar social promovidas pelo liberalismo clássico, uma vez que estas acabavam por enfraquecer a família tradicional fordista.

Pensando no caso brasileiro, compartilhamos com Pinheiro-Machado (2019) a percepção de que a emergência e força da bivalência bolsonarista também podem ser compreendidos como uma espécie de "reação explosiva" aos processos de transformação social pelo qual o Brasil passou nos últimos 15 anos, sobretudo no que se refere à redução das desigualdades, a ampliação do acesso à educação superior, e fortalecimento das lutas feministas, antirracistas e dos grupos LGBTIQA+. Uma interpretação que requer, no entanto, que pensemos nas contradições e limitações que tal quadro, muitas vezes lido como progressista, pode sugerir. Nesse sentido, é importante levar em consideração como tal experiência progressista (não só no Brasil, como em toda América do Sul, no curso das primeiras décadas do século XXI) foi, no fim das contas, catalizadora da reprodução do neoliberalismo. Nessa perspectiva, a opção pelo desenvolvimentismo e a recusa do enfrentamento às questões mais profundas do subcontinente fizeram com que tais governos (a esquerda latino-americana de Lula, Chaves, Kischner e etc), mesmo realizando interferências materiais concretas em situações superestruturais, mantivessem as composições com setores conservadores da sociedade, o que os afastou de suas bases populares (SANTOS, 2020). Somese a isso uma mediação particular das guerras culturais, que no Brasil orientou o debate político a partir de uma simplificação que subordinou as questões sociais e econômicas aos temas morais, gerando um tipo específico de antagonismo detentor de bastante visibilidade e atenção pública: de um lado, a direita liberal conservadora e meritocrática; do outro, a esquerda progressista intervencionista e identitária (GALLEGO, ORTELLADO e MORETTO, 2017).

A partir dessas análises, é fundamental perceber como as propostas de enaltecimento dos valores cristãos familiares e de privatização dos serviços públicos passam a ser abordadas, especialmente pela grande mídia, como projetos diferentes de um mesmo governo, supostamente capaz de articular uma ala ideológica e outra, técnica. Seguindo essa linha de 
raciocínio, alguns veículos falavam sobre a necessidade de setores progressistas da sociedade dialogarem com os atores fundamentalistas do governo, a exemplo de Damares Alves, apontando possíveis pautas em comum e desconectando-os de um projeto maior de sociedade pautado em políticas neoliberais. A falta de aprofundamento sobre a complexidade das relações entre liberais e conservadores no governo e a insistência em caracterizar atores evangélicos como sujeitos irracionais e caricatos frente a um suposto grupo técnico-pragmático localizado, necessariamente, em áreas estratégicas como Economia e Segurança contribui para a reprodução de uma série de falsos binarismos.

Ao apresentar seu argumento de que a então nova ministra deveria ser considerada como interlocutora pela ala progressista da esquerda, a jornalista Tatiana Dias (2018) pondera: “entre as frases polêmicas, um esforço de empatia com a ministra evangélica consegue encontrar vários pontos convergentes com o que a ala progressista pensa” (Ibidem, n/a). Os pontos de convergência que possibilitariam tal interpretação mais empática sobre Alves são tratados pela jornalista como "falas razoáveis" e incluem temas como a divisão de tarefas domésticas, remuneração equivalente para homens e mulheres, combate à violência e ao abuso infantil. Cabe ressaltar, no entanto, como a figura de Damares Alves é tratada com uma condescendência que, mesmo atravessada por uma certa vontade republicana de diálogo, revela muito sobre as diversas assunções acerca do que é uma mulher evangélica e seu lugar no debate público no país.

O que soa razoável para a jornalista é justamente aquilo que alinha o discurso de Damares Alves à ideologia neoliberal que fundamenta a razão política da sociedade a qual a mídia hegemônica legitima - e que, nos parece, muitos veículos alternativos também. Nesse universo de sentido, o trabalho assalariado ou não remunerado (doméstico), como veremos, emerge como um significante muito mais legítimo do que o direito sobre o próprio corpo, no qual a criminalização do aborto não é pensada como uma violência tal como aquela sofrida no ambiente doméstico. Chama a atenção no texto o fato de que a jornalista infere sobre as coisas que Damares Alves não sabe a respeito de seu Ministério. Assim, à medida em que se refere às falas razoáveis da ministra, ressalta dados e informações que, no efeito do texto, devem ser lidos em oposição ao "fundamentalismo evangélico" de Alves. O exemplo abaixo ilustra essa estratégia retórica:

Se a infância e a maternidade forem mesmo uma pauta central da nova ministra, e levadas a sério, com políticas públicas baseadas em evidências, sua gestão vai precisar superar o fundamentalismo evangélico - e tocar em feridas que atormentam homens que não gostam de limpar a casa (Ibidem, n/a, grifo nosso).

REVISTA RELEGENS THRÉSKEIA - 2021 - UFPR 
Ao pensar na sociedade norte-americana, Cooper (2019) afirma que o neoliberalismo se apresenta como uma razão de mundo em que ao Estado deve caber responsabilidades específicas que não atinjam a autoridade familiar. Trabalhando nessa perspectiva, insistimos em nos debruçar naquilo que parece ser o "ponto cego" e mais sensível dos processos de compreensão da atuação de Damares Alves no espectro da bivalência bolsonarista: qualquer tentativa de leitura sobre suas propostas à frente do MMFDH só pode ser assertiva e realista o suficiente se tomar como questão de frente o caráter neoliberal que alimenta noções centrais ligadas aos valores familiares. Dito de outra forma: entendemos que a indicação/acusação de fundamentalismo evangélico para definir a condução das políticas de Direitos Humanos no país hoje, pouco dizem sobre a complexidade do campo e as nuances extremamente sofisticadas com que o ativismo religioso trabalha. Nesse sentido, compartilhamos com Bulgarelli (2020, n/a) a explicação de que "essa distinção entre pautas morais e econômicas diz mais sobre o campo progressista, que propõe essa classificação, do que propriamente sobre como os fenômenos ocorrem no campo conservador".

É por isso também que devemos atentar aos efeitos moralizantes que certas leituras sobre o "fundamentalismo evangélico" suscitam, sobretudo no campo da política institucional atual. Particularmente para esse trabalho, é importante levar em consideração como as narrativas seculares hegemônicas (das quais o feminismo liberal e a esquerda progressista, entre outros, se constituem como portadores) são pautadas por uma moralização do progresso e da emancipação humana, produzindo um cenário em que a "mulher religiosa ainda é vista, pela posição secular, como submissa ou ainda como a marionete de outrem" (DULLO, 2015, p. 194). Nosso ponto, no que se refere à figura de Damares Alves desenhada no texto publicado pelo Intercept, é que a ministra não precisa aprender (ou saber) sobre as coisas que a jornalista, em seu ímpeto salvador, como diria Mahmood (2006), falou. Alves, que acumula uma longa trajetória como ativista nas áreas do direito familiar e da infância, já mostrou que tem repertório e disposição para debater o assunto nos termos de sua formalidade (basta notarmos que a ministra vem participando de todos os fóruns sobre o tema dos Direitos Humanos, sejam eles locais regionais ou internacionais). Se sua atuação soa estranha à sensibilidade secular vigente (ou pelo menos à parte dela), é porque estamos diante, acreditamos, de um sintoma de dupla valência: vê na subjetividade evangélica uma ameaça, mas não enxerga os contorno e densidades da transversalidade neoliberal nessa figura. 
Trazendo para o debate mais um ponto de complexificação, resgatamos quando a Ministra, ainda no início de seu mandato, afirmou que iria às ruas de braços dados com as feministas se a pauta fosse por "salários iguais entre homens e mulheres e a luta contra violência" (OHARA, 2019). Reconhecida justamente por suas falas antifeministas, Damares Alves explicou que certas pautas do movimento poderiam ser abraçadas, "Mas sem o exagero dos seios à mostra. Sem a doutrinação que parece pregar ódio aos homens" (Ibidem). Nesse ponto, evidencia-se a afinidade da ministra com pautas liberais, reforçando tanto a hipótese da bivalência, quanto as complexidades da racionalidade política que sustenta o ativismo religioso do qual Damares é uma emblemática representante.

$\mathrm{Na}$ mesma entrevista, Alves afirmou amar gays e travestis, para nas linhas seguintes, reforçar seu posicionamento anti-ideologia de gênero. Especificamente nesse ponto, cabe refletir como essa suposta contradição é apenas aparente, uma vez que se inscreve com muita precisão na atual ordem discursiva dos Direitos Humanos no país. Ao falar de seu afeto por "gays e travestis", a ministra é muito específica sobre o seu papel institucional em relação ao grupo ("Eu respeito os gays e não tenho nada contra a opção sexual deles") ao mesmo tempo em que coloca essa população num lugar de subalternidade, cuja agência é anulada ("[A]os ideólogos da ideologia de gênero [que] usaram a dor dos gays para impor essa guerra [entre gays e cristão no Brasil, segundo a ministra]"). É importante ressaltar como as duas falas se complementam no sentido de que não geram um posicionamento diretamente antagonista ao direito da população LGBTQIA+, mas funcionam num processo de decantação (esse procedimento será melhor explicado na próxima seção do trabalho) em que direitos não são propriamente negados, mas "ajustados".

É inegável que as falas da ministra assumem como certo o modelo heteronormativo, mas, ao defendê-lo segundo uma suposta natureza binário-generificada de homens e mulheres, Damares Alves não está indicando apenas para o referente bíblico. Ela está apontando também para a própria constituição do capitalismo, cujo trabalho reprodutivo tem sido historicamente relegado a uma função secundária na formação social, implicando na desqualificação generalizada da força de trabalho feminina e no alargamento das desigualdades materiais entre homens e mulheres. Nessa direção, Federici (2021, p. 130) argumenta que as "relações familiares e de gênero têm uma função específica na acumulação do capital, na constituição da subjetividade de trabalhadores e trabalhadoras e na formação da classe".

A família como produto e, ao mesmo tempo, suporte moral para a divisão sexual do trabalho, constitui-se desde a acumulação primitiva como uma noção forjada pelas elites 
políticas e econômicas, apoiadas pela Igreja Cristã, para impor tarefas para homens e mulheres, bem como instituir uma relação de poder dentro da própria classe trabalhadora, de modo que fosse reproduzida pelo proletariado como tarefas e relações naturais. Assim, por trás do discurso da fragilidade e da inferioridade natural, Federici (2017) afirma estar justamente o trabalho não remunerado feminino, marcado historicamente pela exclusão das mulheres das esferas de decisão política. É em nome da reprodução das desigualdades e das hierarquias que a moralidade conservadora serve, sendo parte integrante do que, no capitalismo, vai surgir mais tarde como racionalidade neoliberal.

Mesmo no contexto do capitalismo contemporâneo, trabalho feminino e salários iguais entre homens e mulheres não representam um problema para as pautas conservadoras que integram a racionalidade neoliberal, tampouco revelam um caráter progressista desse movimento. A preservação através da transformação é a condição de existência da família moderna (COOPER, 2019), o que no capitalismo neoliberal implica uma compreensão de família que perpassa noções como liberdade individual e desburocratização do Estado. Independente das condições materiais de seus membros, cabe a eles a responsabilidade pelo provimento da família, um direito e um dever inalienáveis do Estado neoliberal, que trata tudo, inclusive a família, como propriedade privada. De uma criação divina, ela se converte em produto do capital, cujas leis do mercado são a mais sofisticada tradução das leis de Deus, uma herança de alianças históricas entre a Igreja Cristã e o Império Ocidental (HINKELAMMERT, 1991). A família segue o modelo de empresa na mesma medida em que a empresa e a nação passam a ser entendidas como uma grande família cristã. Nesse processo, Brown (2019, p. 141, grifo da autora) afirma que "a privatização econômica neoliberal subverte profundamente a democracia. Ela gera e legitima a desigualdade, a exclusão, a apropriação privada dos comuns e um imaginário democrático profundamente esmaecido".

Segundo Cooper (2019), embora neoliberais e neoconservadores promovam os valores familiares tradicionais por razões a princípio diferentes - os primeiros por motivos econômicos e os últimos por questões morais -, a aliança entre ambos é bastante propositiva no sentido de construir um senso de dever moral natural e Estado mínimo como elementos que se complementam para a criação do equilíbrio social. Apesar de nos ajudar a compreender a relação entre atores de diferentes espectros ideológicos, essa leitura ainda está se referindo a eles como advindo de espaços políticos determinados, cuja aliança vem a se constituir como uma estratégia circunstancial. 


\section{Ativismo neoliberal em nome da família: cultura pública evangélica e a formação de uma agenda político-institucional de depuração de direitos}

Em meio a tantos esforços para compreender o que aconteceu no Brasil para que, em 2018, o projeto bolsonarista fosse escolhido nas urnas (PINHEIRO-MACHADO, 2019; CESARINO, 2020), é comum encontrar análises que indiquem o papel central de Paulo Guedes na construção da credibilidade da candidatura de Jair Bolsonaro. No entanto, é da crítica feminista que vem um apontamento que deve ser levado em consideração, sobretudo quando se trata da execução de tal projeto. Nesse sentido, a figura de Damares Alves à frente do MMFDH vem à tona mais uma vez e nos ajuda a pensar como a agenda neoliberal precisa ser lida a partir de critérios que não tomem a "técnica" como um lugar isolado da "ideologia", ou a "economia" a parte dos "costumes". Ou, como explica Brown (2019, p. 118, grifo da autora) possibilitar às análises a compreensão do "lugar da moralidade tradicional - tanto assegurando a família quanto dela emanando - dentro da razão neoliberal”.

A pauta de Damares Alves à frente do Ministério se apresenta como uma investida sofisticada, que evidencia, tal qual explica Gago (2020), um traço fundamental do neoliberalismo atual: o aprofundamento da crise de reprodução social. Para a autora, a privatização de serviços públicos (ou mesmo a restrição de seu alcance) se traduz "no fato de que essas tarefas (saúde, cuidado, alimentação etc) devem ser supridas pelas mulheres e pelos corpos feminizados como tarefa não remunerada e obrigatória” (Ibidem, p. 266). Há, nesse sentido, um aproveitamento moralizador da crise de reprodução, que se assenta no endividamento dos lares, instituindo um processo de reinvenção estratégica da responsabilidade familiar diante do despojo da infraestrutura pública, permitindo assim uma convergência profunda (e bastante produtiva, diríamos) entre neoliberais e conservadores (Ibidem).

Nesse cenário, em que se reforçam as obrigações e contrapartidas familiares (leiam-se individuais e privadas centradas material e simbolicamente na figura da mulher) no processo de reprodução, as igrejas passam a ter um papel fundamental na gestão dos escassos recursos públicos voltados para o cuidado. Sobretudo no Brasil, o espectro cristão (mas não apenas) nos informa sobre uma série de modalidades de ação na vida pública, que podem ser compreendidas desde a ideia de caridade até a da ação social, por exemplo. No entanto, especificamente no que se refere aos grupos evangélicos, é importante levar em consideração a multiplicidade e dinâmica de seus ativismos políticos e de envolvimento com a sociedade. Usaremos nesse trabalho a categoria de "cultura pública" que Emerson Giumbelli (2013) propõe para pensar as 
formas de presença desse grupo no espaço público. O argumento do autor é que, diferente do catolicismo ou das religiões afrodescendentes, a presença dos evangélicos não se constitui, respectivamente, pela via da "cultura nacional" ou da "cultura étnica". O que faz com que os modos de presença dos evangélicos não se confundam com os modos tidos como constituintes do povo brasileiro, uma vez que não há interesse em usar "a história ou a tradição para comprovar sua presença; sua visão é mais voltada para o futuro. No que diz respeito ao presente, o que temos é uma busca de visibilidade" (Ibidem, p. 21).

Nessa perspectiva, a "cultura pública" evangélica se caracteriza a partir de dois eixos de ação: a ocupação de posições e a proliferação de referências. Sugerimos, assim, que o ativismo desse grupo religioso, que é diverso e pautado por uma multiplicidade de sentidos, encontra no Ministério que articula a Mulher, a Família e os Direitos Humanos um espaço inédito de atuação devido à natureza político-institucional que assume. Se, antes, as posições e referências desse ativismo estavam marcadas por posições embaladas por um forte apelo de minoritização política, é possível argumentar que há em curso um trabalho significativo de reconversão de sua linguagem e tratamento do escopo de sua atuação. Além da transformação sensível dessa atuação, antes movida por interesses majoritariamente fisiológicos, há de se levar em conta também como o redimensionamento da agenda neoliberal na América Latina contribui para o refluxo dos direitos sociais (estes lidos em muitas chaves como uma ofensa aos ditames da meritocracia) em favor do desenvolvimento de políticas de tutela e proteção de vulneráveis (espaço em que a ação do Estado é aceitável, desde que dotada de um sentido moral). Nesse âmbito, a Mulher e a Família que se juntam aos Direitos Humanos do Ministério são mais que sujeitos ideais, são categorias estruturais para a atuação dessa agenda, uma vez que, o que está em jogo não é o simples repúdio aos direitos e sim a sua depuração (DE VITO e PRADO, 2019).

Queremos nos deter com mais atenção no funcionamento desse processo de depuração de direitos que trouxemos de De Vito e Prado (2019) para a análise. Nossa contribuição, nesse sentido, percebe o investimento constante na ideia de vulnerabilidade e ameaça que paira sob os sujeitos desse direito depurado. Nessa perspectiva, crianças, idosos, mulheres, quilombolas, indígenas ou a população cigana são entes em risco, que demandam a ação de um estado protetor, de forte investimento penal. Percebemos na fala de Alves uma forma elaborada de ação desse Estado, que conta com uma expertise reconhecida do ativismo religioso, a capilaridade no alcance de sua ação. É importante ressaltar que a noção de vulnerabilidade experimenta um (re)dimensionamento relevante na construção da proteção de certos grupos, 
tidos na visão da ministra como "invisibilizados". Assim, mesmo quando discute a pauta do enfrentamento à violência contra a população LGBT, Alves "depura" o que seria uma política social em função de níveis mais graves de ameaça ou violência:

[...] Fizemos uma discussão sobre qual é a prioridade do segmento (LGBT). Enfrentamento à violência. Então vamos priorizar isso. Como estão os membros da comunidade na região ribeirinha? Vamos pegar um barquinho e vamos lá na comunidade ribeirinha saber como está o menino gay. Descobrimos que a política pública não chegou para ele. Cadê os gays indígenas? Onde estão as meninas lésbicas indígenas? Por que não se falou nisso no Brasil? Nós descobrimos que eles são hostilizados em algumas comunidades e precisamos cuidar deles. Os direitos, que na área urbana foram tão reivindicados, em algumas regiões não foram garantidos. Então estamos indo lá. Como estão os gays nos quilombos? Como essa população é tratada nos povos tradicionais? E isso tem sido uma inovação e uma revolução: eu pegar um barco e ir a uma cidade como São Gabriel da Cachoeira para saber como está a comunidade LGBTi lá. (SENRA; KRIEZIS, 2019, n/a)

O ativismo de depuração nos informa também sobre o efeito de sentido transparente da ideologia neoliberal, uma vez que, ao ressaltar a vulnerabilidade em detrimento do direito e o reconhecimento da ameaça como condição para legitimação da atuação do Estado, o discurso de Damares Alves demove a própria noção de social do debate político institucional. Uma investida que, se soa fundamentalista ou conservadora aos interlocutores da Ministra em entrevistas da grande imprensa, sinaliza no radar de Wendy Brown (2019) sobre o duplo trabalho neoliberal de desconstrução do social: a eliminação da ideia de que a sociedade de fato existe e que é nela onde as desigualdades (que elevam ou marginalizam certos grupos) se constituem a partir de relações de poder.

Ao enfatizar a vulnerabilidade e a ameaça, a decantação dos direitos possui de fato uma positividade, produz os sujeitos a serem protegidos, na mesma medida em que abre a possibilidade de narrativas exemplares, de superação de condições adversas, em que as contingências históricas, políticas, econômicas ou de qualquer outra ordem, contam muito pouco na compreensão da realidade. É o caso da noção de empoderamento que Alves propõe. Tema de grande valor na agenda feminista, a ministra faz uma inflexão neoliberal sobre o termo, cujo sentido de poder é exterior a qualquer concepção de social. "Tem mulher mais empoderada no Brasil do que eu? Uma menina que vem lá de baixo, que não tem sapato para estudar, vai a uma escola, sofre violência, é discriminada e chega a ser ministra? Isso é empoderamento da mulher" (SENRA; KRIEZIS, 2019, n/a).

Outra expressão importante sobre o ativismo liberal de Damares Alves e de seu suposto ministério ideológico é o acúmulo de uma expertise valiosa, centrada na relação entre religião 
e política a partir de uma lente voltada para o papel da mulher e seu valor na configuração familiar. Como discutimos na seção anterior, a atual ministra possui uma larga experiência no que se refere ao trabalho de apoio parlamentar e jurídico, uma atuação típica dos "bastidores do poder" que deu repertório e sustentação para sua performance pública. Numa análise sobre a construção da direita evangélica nos Estados Unidos, a historiadora Emily Suzane Johnson (2020) explica como diversos grupos liderados por mulheres assumiram um papel central no trabalho de base, ao construírem argumentos que apelavam sobretudo ao papel das mulheres como esposas e mães. Segundo a autora, a atual configuração da direta religiosa americana (e sua capacidade de se capilarizar em outras paróquias pelo continente) deve muito à liderança feminina que passou a ganhar força no pós-guerra nos quadros evangélicos. Para além do reforço dos valores familiares e da contenda contra o feminismo, esse ativismo é marcado por um forte apelo meritocrático individualizante, que vê como desperdício ou autoritarismo a atuação do Estado em temas como educação ou assistência, bem como adota um posicionamento indiferente ou reativo em relação às políticas raciais.

Ao mesmo tempo, não se pode ignorar o quanto a agenda liberal encontra guarida nas pautas de empoderamento feminino que Damares recorrentemente gosta de ressaltar e que se reproduzem de maneira bastante eficiente entre as denominações evangélicas (sobretudo pentecostais). Como explica Jaqueline Teixeira (2016), ao mesmo tempo em que muitas práticas teológicas pentecostais fortalecem o papel da mulher no modelo nuclear de família, também abrem espaço para uma redefinição dos gêneros através de incentivos no cuidado da aparência e da visibilidade profissional. Isso porque o forte apelo à profissionalização e ao empreendedorismo das mulheres "emergem não mais como uma característica de oposição ao bem-estar da família, mas sim como extensão das atividades da mulher no seio familiar" (Ibidem, p. 215). Uma mulher virtuosa, por assim dizer, não só zela pela união e estabilidade da família como também deve cooperar para com a sua prosperidade, devendo ser também bemsucedida no campo profissional.

Um ponto importante do funcionamento desse ativismo político encampado por Damares Alves está no que Izabela Kallil (2020) configurou como a absorção da agenda antigênero (essa de via negacionista) pela agenda da família (de cunho afirmativo). Assim, as pautas contra a ideologia de gênero não desapareceram completamente, mas se reconfiguraram pactuando na "família" uma categoria estratégica, capaz de catalisar demandas sensíveis como a atuação do Estado em questões como seguridade, educação e saúde (Ibidem, p. 47), num movimento que já identificamos na chave da depuração. Com essa percepção, a autora nos 
mostra que essa nova composição institucional demonstra habilidades que vão além da mera remoção do significante gênero (e toda constelação de nomes que circulam em torno dele) dos documentos oficiais e sim uma proposição nova para a ideia de Direitos Humanos. Por usar de maneira habilidosa a linguagem jurídica e seu repertório, não há oposição a direitos e sim uma seleção dos que são protegidos por ele, reforçando a ideia de vulnerabilidade e ameaça e enaltecendo narrativas de superação que visam o mérito do sujeito "empoderado".

Se olharmos para além do "espantalho do gênero", poderemos ver que o MMFDH tira dos bastidores e coloca na linha de frente da política institucional uma prática de forte conotação liberal, em que o investimento em si mesmo é fator primordial para o sucesso e reconhecimento do sujeito. Ao mesmo tempo, faz isso enquanto enfatiza a centralidade da Família nessa tarefa, depurando em meio ao escopo do Estado as obrigações sociais de assistência e proteção em casos de vulnerabilidade e ameaça.

Há, nesse ativismo, uma linguagem que há muito vem sendo observada nos meios religiosos pentecostais em que a devoção incentiva práticas ambiciosas de prosperidade material. Em seu turno, o significante Mulher na sigla funciona de maneira polissêmica, uma vez que remete a temas importantes da agenda feminista e também marca uma distinção inegociável contra as ameaças que "o gênero" pode infligir. Nesse sentido, não há na atuação de Damares Alves à frente do Ministério uma fala contra a legalidade do casamento entre pessoas do mesmo sexo, por exemplo, mas abundam em suas declarações públicas denúncias contra a corrupção da "ordem social familiar”. Assim, é possível afirmar que a ministra não só se inscreve numa "cultura pública" evangélica pela mão dupla da presença e da referência, como também reforça essa mesma cultura a partir de outros lugares, postulando que a Mulher e a Família sejam entes não só protegidos, mas sobretudo produtivos.

\section{Considerações finais}

Perguntada sobre a compatibilidade entre seu perfil de ativista religiosa e as tarefas institucionais à frente do então recém-criado Ministério da Mulher Família e Direitos Humanos, Damares Alves rebate com uma resposta que oferece importantes marcadores sobre a complexidade da atuação política do campo evangélico no país. A ministra lembra ao interlocutor sua trajetória prévia na cruzada contra a "ideologia de gênero" ao afirmar que não está "fazendo esse enfrentamento agora porque sou ministra. Esse enfrentamento, [...] eu faço de uma forma veemente como ativista". Mais à frente, no entanto, pondera sobre essa dupla 
identidade ao dizer que seu lado ativista está adormecido, uma vez que se tornou ministra: "Porque agora eu falo como Estado, meu discurso é de Estado" (Ibidem). Reconhecemos nessa fala uma ponderação importante no que diz respeito ao tema central do trabalho que apresentamos aqui: o ativismo político do campo evangélico, tomado a partir da bivalência bolsonarista, assume um caráter político institucional e, por isso, deve ser considerado a partir de leituras que problematizem noções apriorísticas sobre conservadorismo e progressismo.

Nesse sentido, mostramos o efeito de sentido transparente da ideologia neoliberal não só no discurso da ministra quanto nas análises e inferências que surgiram de suas falas e que formaram o corpus do trabalho. Trata-se de uma discursividade tão eficiente que, quanto mais Alves expressava ou enfatizava a envergadura neoliberal de sua visão de mundo e de "discurso de Estado", menos ela era tida como conservadora ou mesmo fundamentalista. Ao sugerir pontos de convergência entre o que "a ala progressista pensa" e as propostas da ministra (DIAS, 2019), ou apontando "posições que poderiam ser associadas a vozes progressistas" (SENRA; KRIEZIS, 2019, n/a), o material de análise abre um grande espaço de reflexão sobre as astúcias do discurso político de nosso tempo.

A bivalência da plataforma bolsonarista foi levada em consideração na compreensão do corpus. $\mathrm{O}$ atual alcance do ativismo do campo evangélico atravessa espaços fundamentais da política institucional no país e, por isso mesmo, precisa ser compreendido para além da leitura que interpreta esses atores se não como oportunistas, muitas vezes como despreparados, lunáticos etc. Nesse sentido, é bastante sintomática a prescrição de Dias (2019) sobre o que a então nova ministra precisa saber/fazer para atuar em seu gabinete: "Se Damares Alves pretende proteger a infância e as mulheres, então que leve em conta a realidade para isso" (DIAS, 2019). O significante "realidade" reverbera em nós um incômodo, mas sugere também um sintoma. Isso porque, na medida em que acusa a ministra de algo, revela também o que a acusadora não compreende ou simplesmente assume como certo, como dado.

Entender como esse ativismo se move por densidades políticas tão complexas é uma tarefa que precisa reconhecer na família um papel estruturante. Apresentada como a esfera privada, longe do domínio - e das responsabilidades - do Estado, a família, além de ser uma ideia produtiva para os projetos neoliberais de privatização dos serviços públicos, também institui a naturalização do trabalho não remunerado de mães, esposas e filhas. Nessa perspectiva, qualquer possibilidade de atuação do Estado dentro da estrutura familiar só poderia ser aceitável se o fosse em nome de uma ameaça. Entendemos, a partir da noção de depuração 
de direitos, que a vulnerabilidade é fundamental para o neoliberalismo, uma vez que ela autoriza a presença do Estado, numa visada cautelar, punitiva e policial.

Percebemos, assim, como a insistência pela vulnerabilidade e a expansão pelos territórios mais longínquos, como as comunidades ribeirinhas ou os quilombos por exemplo, não tem por objetivo questionar direitos, mas retirar do Estado a função distributiva que permite que as desigualdades possam ser remediadas ou atenuadas (BROWN, 2021, n/a). Assim, o indivíduo situado na família (e não na sociedade) produz a narrativa perfeita para o neoliberalismo, mais até do que para qualquer projeto do que se possa chamar de fundamentalismo evangélico: individualista, ele ataca os direitos sociais em nome do mérito e se orgulha de sua trajetória. O “empoderamento" de Damares (SENRA e KRIEZIS, 2019, n/a) é um exemplo claro disso.

Por fim, queremos ressaltar que o tema do ativismo político do campo evangélico abre possibilidades de interpretações a respeito das relações entre política e religião no atual cenário brasileiro. A incidência da pandemia a partir de 2020 é, em nossa percepção, um recorte temporal valioso, que pode indicar se houve alargamentos ou possíveis descontinuidades em relação ao que constatamos em 2019, ano em o MMFDH estava estreando no espaço político institucional. Seria interessante perceber, por exemplo, como o sentido de vulnerabilidade é desdobrado no discurso da ministra diante do enfrentamento da doença. De antemão, sabemos através do corpus de análise que a "ativista adormecida" está atenta e conhece seu lugar institucional. Como afirmou em entrevista para a Folha (OHARA, 2019), todas as causas que a mobilizam estão "aqui dentro do coração e quero lembrar que foram essas causas que me trouxeram aqui”.

\section{Referências}

BRASIL. Decreto n 7.037 , de 21 de dezembro de 2009. Aprova o Programa Nacional de Direitos Humanos - PNDH-3 e dá outras providências. Lex: coletânea de legislação: edição federal, Brasília, 2009.

BROWN, Wendy. Explicando nossos sintomas mórbidos políticos. Entrevista concedida a Daniel Denvir. Tradução de Letícia Cesarino. Revista Jacobina, 30 jun. 2021. Disponível em: https://jacobin.com.br/2021/06/explicando-nossos-sintomas-morbidos-politicos/. Acesso em: 15 jul. 2021.

BROWN, Wendy. Nas ruínas do neoliberalismo: a ascensão da política antidemocrática no ocidente. Tradução Mario A. Marino e Eduardo Altheman C. Santos. São Paulo: Editora Filosófica Politeia, 2019. 
BULGARELLI, Lucas. Entrevista: "Damares e Guedes são parte do mesmo projeto político", diz pesquisador. Entrevista concedida a Rosana Pinheiro-Machado. The Intercept Brasil, 1 set. 2020. Disponível em: https://theintercept.com/2020/09/01/entrevista-lucas-bulgarellidamares-guedes-conservadorismo/. Acesso em 22 de fev. de 2020.

BURITY, Joanildo. A onda conservadora na política brasileira traz o fundamentalismo ao poder? In: ALMEIDA, Ronaldo; TONIOL, Rodrigo. Conservadorismos, fascismos e fundamentalismos: análises conjunturais. Campinas: Editora da Unicamp, 2018, p. 15-66.

CESARINO, L. Identidade e representação no bolsonarismo. Corpo digital do rei, bivalência conservadorismo-neoliberalismo e pessoa fractal. Revista de Antropologia, [S. 1.], v. 62, n. 3, p. 530-557, 2019. DOI: 10.11606/2179-0892.ra.2019.165232. Disponível em: https://www.revistas.usp.br/ra/article/view/165232. Acesso em: 01 ago. 2021.

COOPER, Melinda. Family values: Between Neoliberalism and the New Social Conservatism. New York: Zone Books, 2019.

DARDOT, Pierre; LAVAL, Christian. A nova razão do mundo: ensaio sobre a sociedade neoliberal. Tradução de Mariana Echalar. São Paulo: Boitempo, 2016.

DE VITO, R.; PRADO, M. A. (2019) 'Direitos humanos, gênero e sexualidade: uma ministra que não brinca em serviço'. Sexuality Policy Watch, 19 June [online]. Disponível em: https://sxpolitics.org/ptbr/direitos-humanos-genero-e-sexualidade-a-ministra-que-nao-brincaem-servico/9402. Acesso em: 15 abr. 2021.

DIAS, Tatiana. Damares Alves precisa perder o medo de meninos brincando de boneca. E a esquerda precisa conversar com ela. The Intercept Brasil. 8 Dez 2018. Disponível em: https://theintercept.com/2018/12/07/damares-alves-esquerda/. Acesso em: 01 ago. 2021.

DULLO, Eduardo; QUINTALHANA, Rafael. 2015. A sensibilidade secular da política brasileira. Debates do NER, vol. 16, n. 27, p. 173-198. Disponível em: < https://doi.org/10.22456/1982-8136.56478> Acesso em: 15 Jul 2021.

FASSIN, É. (2020). 'Anti-gender campaigns, populism and neoliberalism in Europe and Latin America'. Revue internationale et stratégique, 3(3), [online]. Disponível em:: https://doi.org/10.3917/ris.119.0079. Acesso em: 13 ago. 2021.

FEDERICI, Silvia. O calibã e a bruxa: mulheres, corpo e acumulação primitiva. Tradução Coletivo Sycorax. São Paulo: Elefante, 2017.

O patriarcado do salário: notas sobre Marx, gênero e feminismo, volume 1. Tradução Heci Regina Candiani. São Paulo: Boitempo, 2021.

GAGO, Verónica. A potência feminista ou o desejo de transformar tudo. São Paulo: Elefante, 2020.

GALLEGO, Esther S., ORTELLADO, Pablo e RIBEIRO, Marcio. 2017. “Guerras culturais e populismo antipetista nas manifestações por apoio à Operação Lava Jato e contra a reforma de previdência”. Em Debate, vol. 9, n. 2, p. 35-45. Disponível em:

https://bdpi.usp.br/item/002854247 
GIUMBELLI, Emerson. Cultura Pública: evangélicos y su presencia en la sociedad brasileña. Sociedad Y Religion, vol. XXIII, n. 40, p. 13-43. Disponível em: https://lume.ufrgs.br/handle/10183/106609. Acesso em: 30 jul. 2021.

HINKELANMERT, Franz J. Sacrifícios humanos e sociedade ocidental: Lúcifer e a besta. Tradução João Rezende Costa. Revisão Iranildo B. Lopes. São Paulo: Paulus, 1995.

JOHNSON, Emily Suzanne. This is Our Message: Women's Leadership in the New Christian Right. New York: Oxford University Press, 2020.

KALIL, Isabela. (2020). 'Políticas antiderechos en Brasil: neoliberalismo y neoconservadorismo en el gobierno de Bolsonaro'. In: SANTANA, A. T. Derechos em riesgo em América Latina: 11 estudios sobre grupos neoconservadores. Quito, Ediciones desde abajo, pp. 35-54.

LACLAU, Ernesto. "Posfácio". In: Pós-Estruturalismo e Teoria do Discurso: em torno de Ernesto Laclau. Mendonça, D; Rodrigues, L. (Org.). Porto Alegre: EDIPUCRS, 2008.

LACLAU, Ernesto; MOUFFE, Chantal. Hegemonia e Estratégia Socialista: por uma política democrática radical. São Paulo: Editora Entremeios, 2015.

MAHMOOD, S. Politics of Piety: The Islamic Revival and the Feminist Subject. Oxford: Princeton University Press, 2006.

OHARA, Carlos. Posso ir às ruas de braços dados com feministas por salários iguais, diz Damares. Folha de São Paulo, São Paulo, 18 fev. 2019. Poder. Disponível em: https://www1.folha.uol.com.br/poder/2019/02/posso-ir-as-ruas-de-bracos-dados-comfeministas-por-salarios-iguais-diz-damares.shtml. Acesso em: 01 ago. 2021.

RANGEL, Ricardo. Bolsonaro e sua "ala técnica". Veja. 03 Jul 2020. Disponível em: < https://veja.abril.com.br/blog/ricardo-rangel/bolsonaro-e-sua-ala-tecnica/> Acesso em: $15 \mathrm{Jul}$ 2021.

ROCHA, Lucas. Facebook resgata vídeo em que Guedes espalha Fake News sobre universidades: "Ensinam sexo para crianças". Revista Fórum. 10 Maio 2021. Disponível em: $<$ https://revistaforum.com.br/politica/facebook-resgata-video-em-que-guedes-espalha-fakenews-sobre-universidades-ensinam-sexo-para-criancas/> Acesso em: 10 Ago 2021.

SANTANA, Ailynn Torres. Neoconservadurismos en América Latina: análisis desde la crisis. IN: ___ et al (Orgs.). Derechos em riesgo em América Latina: 11 estudios sobre grupos neoconservadores. Quito, Ediciones desde abajo, pp. 9-34.

SANTOS, Fábio. Uma história da onda progressista sul-americana (1998-2006). São Paulo: Elefante, 2020.

SENRA, R; KRIEZIS, E. (2019). 'Damares Alves: 'Tem mulher mais empoderada no Brasil do que eu?'. BBC News Brasil. 18 dez. 2019. Disponível em: https://www.bbc.com/portuguese/internacional-50800983. Acesso em: 10 mar. 2021. 
SENRA, Ricardo; KRIEZIS, Elisa. Damares Alves: 'Tem mulher mais empoderada no Brasil do que eu?'. Época, O Globo, 18 dez. 2019. Disponível em: https://oglobo.globo.com/epoca/brasil/damares-alves-tem-mulher-mais-empoderada-nobrasil-do-que-eu-24145477. Acesso em: 13 ago. 2021.

TATE, Winifred. A dark day in Colombia. Nacla. 04 out. 2016. Disponível em: https://nacla.org/news/2016/10/04/dark-day-colombia-0. Acesso em: 01 ago. 2021.

TEIXEIRA, Jaqueline. A hermenêutica dos corpos: notas sobre o pastorado das mulheres na Igreja Universal. In: MONTERO, Paula. Religiões e Controvérsias Públicas: experiências, práticas sociais e discursos. Campinas: Editora Unicamp-Terceiro Nome, 2016, p. 207-230.

VIVAS, Fernanda. 'Estado é laico, mas esta ministra é terrivelmente cristã', diz Damares ao assumir Direitos Humanos. G1 Política. 02 Jan 2019. Disponível em: < https://g1.globo.com/politica/noticia/2019/01/02/estado-e-laico-mas-esta-ministra-eterrivelmente-crista-diz-damares-ao-assumir-direitos-humanos.ghtml> Acesso em: 01 Ago 2021. 